\title{
Product-Library-Derived Specification Parameters in Building Information Models Augmentation
}

\author{
Erezi Utiome \\ Creative Industries Faculty, Queensland University of Technology, Brisbane QLD 4000, Australia
}

\begin{abstract}
This paper conceptualizes a framework for bridging the BIM (building information modelling)-specifications divide through augmenting objects within BIM with specification parameters derived from a product library. We demonstrate how model information, enriched with data at various LODs (levels of development), can evolve simultaneously with design and construction using different representation of a window object embedded in a wall as lifecycle phase exemplars at different levels of granularity. The conceptual standpoint is informed by the need for exploring a methodological approach which extends beyond current limitations of current modelling platforms in enhancing the information content of BIM models. Therefore, this work demonstrates that BIM objects can be augmented with construction specification parameters leveraging product libraries.
\end{abstract}

Key words: BIM, specifications, product library, LOD.

\section{Introduction}

BIM (building information modelling), a process of digitally representing the abstracted attributes of buildings, is redefining the world of construction $[1,2]$. Ongoing efforts in the construction industry are targeted at enriching and exploiting building information models for increased efficiency and productivity gains. Indeed, there is evidence that such efforts have given rise to outcomes, such as: industry-wide acknowledgment of improved team collaboration through visualization [2], increased accuracy in building design and construction through clash-detection as well as savings in construction cost and time [1].

In the context of the whole building lifecycle however, such gains are, arguably, automational rather than informational [3]. Table 1 is a contextual summary of the extent and impact of the automational and informational benefits of BIM on the building life cycle phases.

Based on the matrix (Table 1), automational

Corresponding author: Erezi Utiome, Ph.D., research fields: building information modelling, specifications cost planning, project management and construction management. E-mail: e.utiome@qut.edu.au. benefits derive from exploiting functionalities of BIM tools during design and construction, while informational benefits accrue from leveraging modelled information for addressing stakeholders' requirements throughout a building's useful life-conceptualization, design and construction through to occupancy and even, its eventual deconstruction.

\section{Construction Specifications: An Overview}

Construction specifications are a class of building information ${ }^{1}$ crucial to the lifecycle of buildings which capture information related to material quality and the associated workmanship necessary for project completion [4]. Therefore, among other functions, information from a building specification is useful for ensuring that a BIM model accurately represents a facility: as specified, as designed and as-built.

According to the Construction Specifications Institute [5], the use of formal specification documents, as records from sacred texts show, date as

\footnotetext{
${ }^{1} \mathrm{~A}$ basic understanding of building information modelling and related concepts like IFCs (industry foundation classes) and COBie (construction operations building information exchange) is assumed throughout this document.
} 
Table 1 BIM lifecycle-impact matrix.

\begin{tabular}{lllll}
\hline Benefit versus impact scale & & \multicolumn{2}{c}{ Extent of impact } \\
\hline Impact criteria & Impact phase(s) & Short-term & Mid-term & Long-term \\
\hline Cost savings [6] & Conceptual-EOL/refurbishment & $\mathrm{X}$ & $\mathrm{X}$ & $\mathrm{X}$ \\
Time savings [6] & Conceptual-EOL/refurbishment & $\mathrm{X}$ & $\mathrm{X}$ & $\mathrm{X}$ \\
Improved communication [6] & Conceptual-EOL/refurbishment & $\mathrm{X}$ & $\mathrm{X}$ & $\mathrm{X}$ \\
Improved coordination [6] & Conceptual-EOL/refurbishment & $\mathrm{X}$ & $\mathrm{X}$ & $\mathrm{X}$ \\
Speedy evaluations [7] & Design-FM & $\mathrm{X}$ & $\mathrm{X}$ & $\mathrm{X}$ \\
Controlled whole-lifecycle costs and environmental data [8] & Conceptual-EOL/refurbishment & $\mathrm{X}$ & $\mathrm{X}$ & $\mathrm{X}$ \\
Improved customer service [8] & Design-FM & $\mathrm{X}$ & $\mathrm{X}$ & $\mathrm{X}$ \\
Automated assembly [8] & Design and construction & $\mathrm{X}$ & $\mathrm{X}$ & \\
Improved design [8] & Design & $\mathrm{X}$ & & \\
\hline
\end{tabular}

$\mathrm{EOL}=$ end of life; $\mathrm{FM}$ = facility management.

Source: author.

far back as transcripts outlining the building of Noah's Ark. This view is corroborated by the fact that the history of specifications can be traced from the Athenian Acropolis, through to the hieroglyphics inscribed on papyri from ancient Egypt, on to standardized paper documents [9] and, more recently, PDF documents [10]. Therefore, in the period since their use were first recorded, the media and general methodology for conveying, accessing and expressing the content of construction specifications have undergone only moderate changes, relative to other allied construction processes. Moreover, the majority of specification documents are still mainly textual and only adjusted with successive project implementations [11].

Therefore, although the media for representing the content of specifications have transitioned from the papyrus to more modern information platforms, the paradigm where specifying is considered as a separate process, almost entirely exclusive of such technological tools as BIM software, is an aspect of construction specification that remains largely unchanged [12].

Depending on their contents, construction specifications, as identified by the Construction Specifications Institute [5], are generally grouped into one or more of five broad areas, namely:

(1) descriptive specifications which give detailed descriptions of material properties, the workmanship required and the manner in which they are to be installed on the construction site. An example of a descriptive specification is structural concrete-less than or equal to: half $(1 / 2)$ the smallest dimension between forms, one third (1/3) the slab depth or three quarters $(3 / 4)$ of the minimum clearance between each reinforcing bar. Total size shall be three quarters (3/4) of an inch;

(2) performance specifications which describe the expected outcomes, the basis for making judgments on performance and the verification method(s). An example of a performance specification is panel fire rating: Class A flame spread rating according to ASTM E 84 [13];

(3) reference standard specifications which utilize well-established standards as the basis for the specification of products or processes. An example of a reference standard specification is fire-resistive gypsum board: ASTM C 1396 [14]: Type X (special fire-resistant), typical 48 in. wide and $5 / 8$ in. thick (1/2 inch thick, proprietary fire-resistive where indicated), square cut ends and tapered sides;

(4) proprietary specifications which describe proprietary information. An example of a proprietary specification is toilet seat cover dispensers: surface-mounted Bobrick B-221 or equal, Type 304 stainless steel, satin finish;

(5) mixed specifications which use of more than one specification formatting style in a specification 
document.

Collectively, these specifications are the prime enablers of a BIM approach to specification [15]. Irrespective of this classification, however, specification documents generally comprise three main parts: general requirements, product requirements and execution requirements [15].

Therefore, rather than the mere use of the features of BIM software during design and construction, a long-term benefit of BIM relates to the iterative, sustained application of the information content of building models for decision making throughout the useful life of buildings until their refurbishment or eventual deconstruction.

However, realizing the long-term benefits of BIM will prove challenging if model and specification information are not systematically integrated in a manner that reflects the different phases unique to the building lifecycle. This work proposes, therefore, that further benefits of BIM may be realized through a systematic and sustained integration of specification information that is useful in all phases of a building's lifecycle, from conceptualization through its operation and eventual deconstruction, as shown in Fig. 1.

\section{Current and Contextual Approaches}

There is increased awareness of the short-term implications of model information for building design and construction as well as longer-term implications for facilities management [16]. Such early focus on BIM-centric information underscores the need for specification information from the point when the client's brief is produced to the eventual refurbishing or demolition of buildings [16].

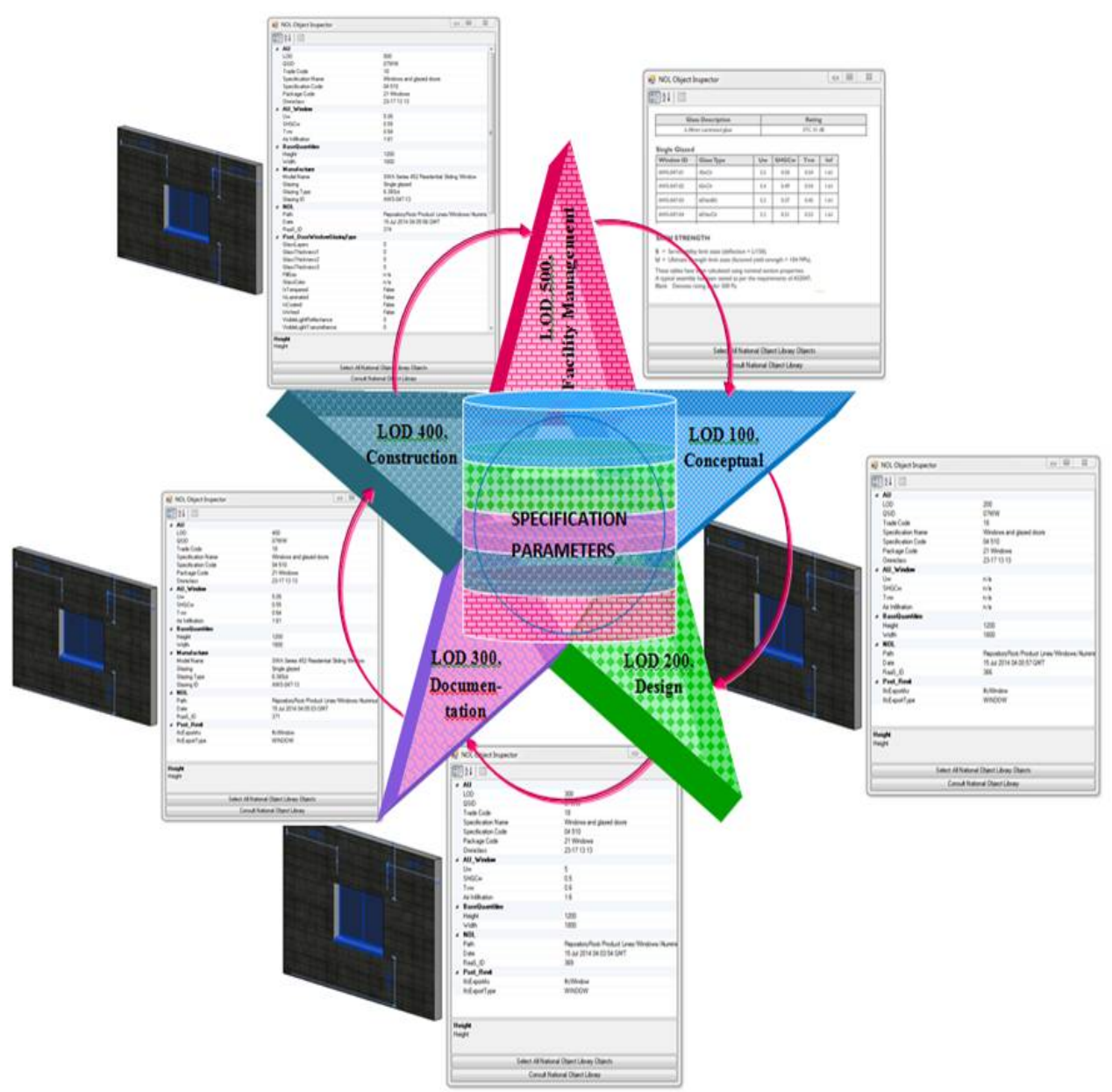

Fig. 1 A BSL (BIM-specifications-LOD (levels of development)) framework (window object example).

Source: author. 
Yet, these sets of specification information have not been explicitly considered as much as other rapidly improved aspects of BIM applications [17]. Current studies indicate that there are no standardized approaches to integrating specification information within BIM environments and such specifications information are, at best, mere references and adapted in ways that are non-replicable and non-integrated $[10,15]$.

An LOD refers to the extent to which the geometric and non-geometric components of model objects have been defined [18]. Although authors differ as to the definition and content of LODs [19-21], this paper concerns itself with developing a systematic approach to embedding specification information in models at different LODs based on LOD definitions by NATSPEC (National Specification System of Australia) [22], as indicated in the BSL framework (Fig. 1).

A summary of the LOD requirements for a window object, as proposed by BIM Forum [20] and NATSPEC [22] is shown in Table 2. The shaded region in Fig. 2 further shows (graphically), the flow-on effect of information at the early phases of the building lifecycle on the information needs throughout the rest of the building lifecycle phases (information granularity is gradual between LOD phases).

On this premise, the following sections of this paper present a method for embedding specification information in BIM models from a product library.

Thus, each model object (a window object, for example) is a self-contained repository of information that may be accessed and updated at various stages of a building's lifecycle to support the technical and non-technical decisions in building design, construction and maintenance.

\section{Methodology}

In this section, we show that information within BIM models (using Revit Architecture as a tool) may be systematically enhanced by utilizing specification information from a product library.

The augmentation is achieved by first enriching a generic Revit $(900 \mathrm{~mm} \times 1,800 \mathrm{~mm})$ fixed window object and then transforming it to a proprietary Aluminium $(1,200 \mathrm{~mm} \times 900 \mathrm{~mm})$ sliding window object at various levels of definition.

To explore the outcomes of embedding specification information within building information models, we utilize the following tools:

- a BIM authoring software-Revit;

- a COBie-formatted template;

- a product library [23].

There are a growing number of software vendors who provide stand-alone or suites of BIM-authoring software [24] to a variety of industry stakeholders. For illustrative purposes, however, the software chosen in this paper is Autodesk's Revit, as it is widely used in industry.

To enable the attachment of specification data to IFC-based object geometry in the product library without loss of integrity, we adopt a COBie approach. COBie is a non-proprietary dataset documentation format widely used for information sharing and documentation [25].

Table 2 LOD-lifecycle matrix (derived from NATSPEC [16]).

\begin{tabular}{lll}
\hline LOD & Definition & Lifecycle phases \\
\hline LOD 100 & Overall building massing indicative of height, volume, location and orientation & Conceptual \\
\hline LOD 200 & $\begin{array}{l}\text { Generalized systems or assemblies with approximate quantities, size, shape, location and } \\
\text { orientation }\end{array}$ & Design \\
\hline LOD 300 & Specific assemblies that are accurate in terms of size, shape, location, quantity and orientation & Design \\
\hline LOD 400 & $\begin{array}{l}\text { Specific assemblies that are accurate in terms of size, shape, location, quantity and orientation } \\
\text { with complete fabrication, assembly and detailing information }\end{array}$ & Construction \\
\hline LOD 500 & $\begin{array}{l}\text { Constructed assemblies, actual and accurate in terms of size, shape, location, quantity and } \\
\text { orientation }\end{array}$ & Facility management \\
\hline
\end{tabular}




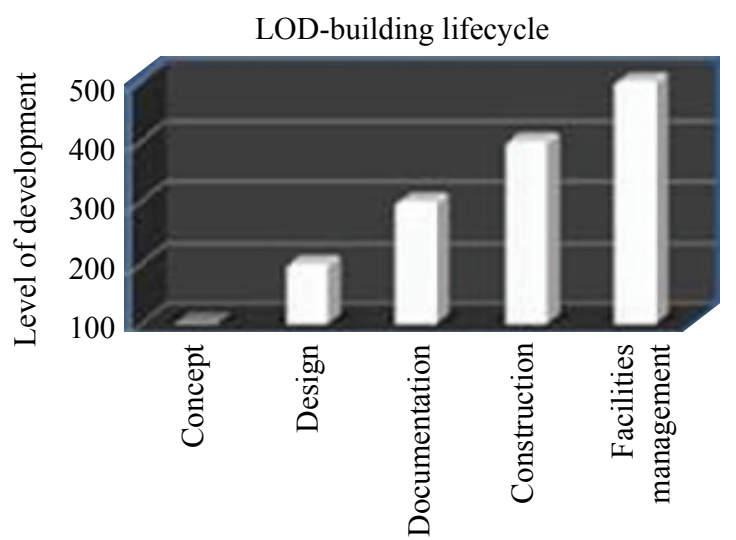

Fig. 2 Specifying at different LODs.

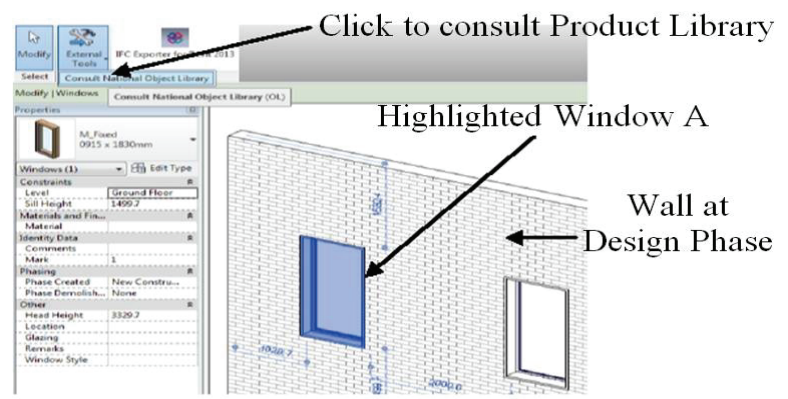

Fig. 3 Window A.

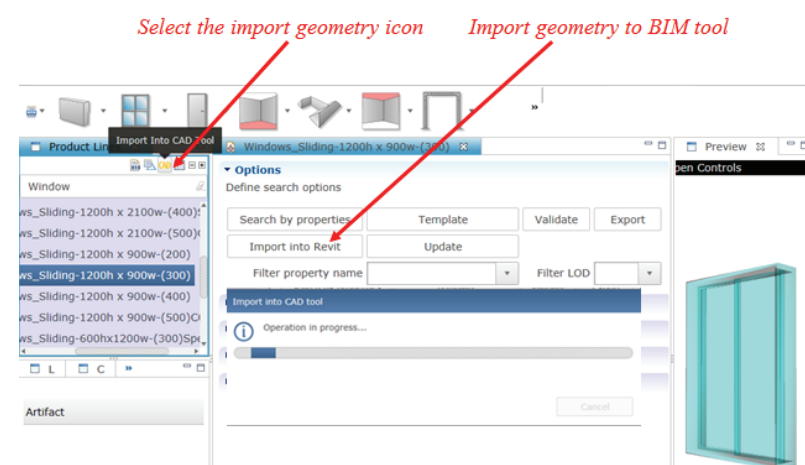

Fig. 4 Importing $1,200 \mathrm{~mm} \times 900 \mathrm{~mm}$ sliding window specs to Window A.

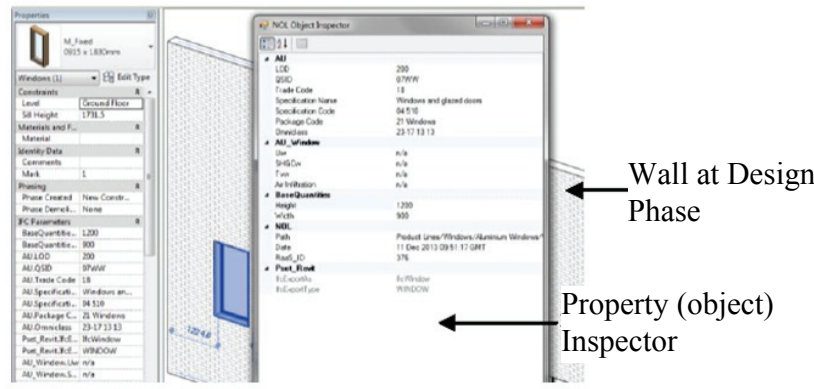

Fig. 5 Imported specs for Window A at LOD 200.

A comprehensive discourse on BIM authoring tools and COBie lies outside the scope of this work.
However, a detailed discussion of the underlying processes for generating the content of the product library is presented in Ref. [26].

Together, the COBie-derived specification information and the IFC window geometry make up the product line template within the product library. The information that is added to the spreadsheet includes the information normally included in a written specification, such as relevant standards, workmanship, materials and manufacturer requirements.

Figs. 3-7 and the accompanying guidance notes illustrate a step-wise methodology for achieving BIM-specification integration. In all instances, the underlying assumption is that each window object was originally at LOD 100 as defined in the LOD-lifecycle matrix (Table 2):

(1) Step 1: select window (Fig. 3) and select the "national object library" icon on the Add-Ins tab within Revit;

(2) Step 2: select the desired window at the appropriate LOD (in this instance, 200) from the product listing in the product library, then click on the "Import to Revit" icon. The new specification information/property sets for Window A are thus viewable in the Revit properties panel and through the property inspector as shown in Fig. 5;

(3) Step 3: repeat Steps 1 and 2 above, selecting LOD 300 in this instance (Fig. 6);

(4) Step 4: repeat Steps 1 and 2, selecting LODs 400 and 500 for Windows C and D, respectively (Fig. 7).

\section{Results and Discussions}

Although the approach described in this paper is simplistic, it is scalable. The results show that specification information can be embedded in BIM models at various levels of development while accurately meeting the information needs of the building lifecycle phase at which the specifications occur.

Further benefits may be realized through model 


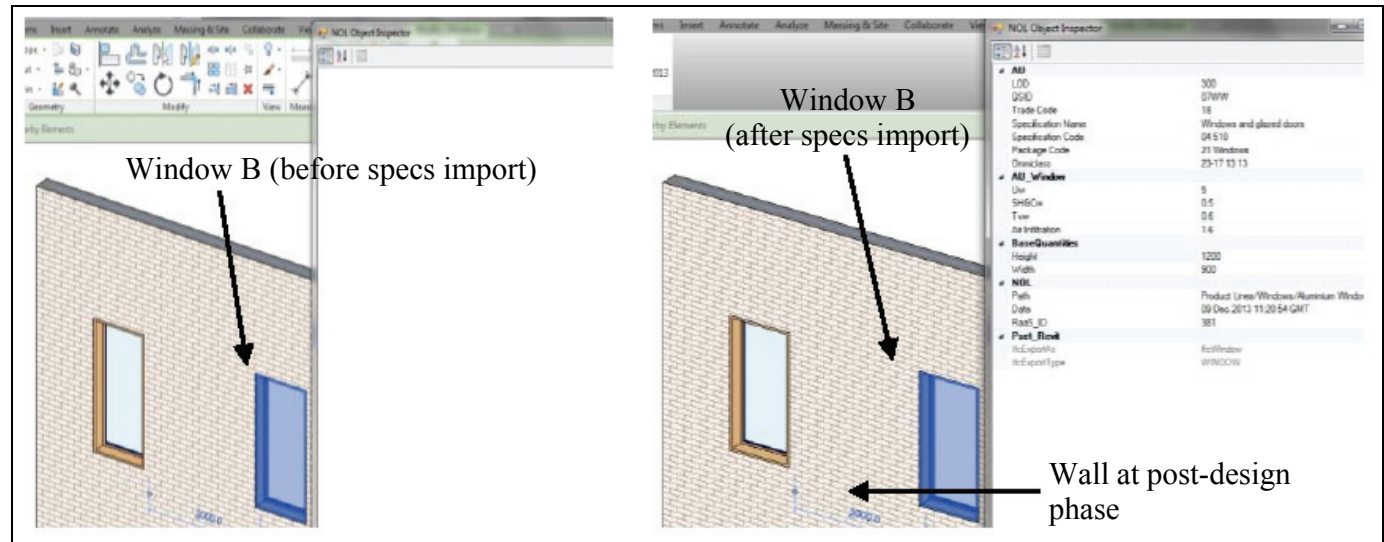

Fig. 6 Window B (at LOD 300) — viewed with the property inspector panels before and after embedding of new specs from the product library.

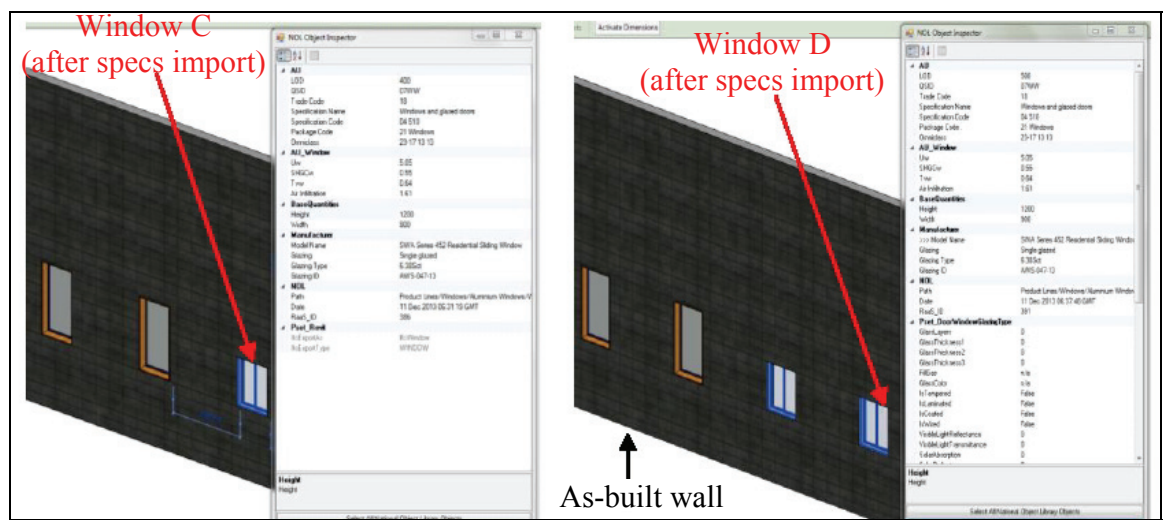

Fig. 7 Windows C (LOD 400) and D (LOD 500): both viewed with the property inspector after embedding new specification information from the product library.

design approaches which systematically caters to the process-flow in the building lifecycle-from the conceptual phase until the end of its useful life-by augmenting model information with appropriate specification parameters at different levels of development.

By implication, the following prerequisites must be met to assure sustained success in the implementation of the augmented approach to specifying for BIM models:

- Access to product information. A substantial part of most specification documents revolve around products. These products are usually described and specified based on the information prescribed by manufacturers. Therefore, it is essential that manufacturers allow designers and users sufficient access to modelled product information. Evidence of such productive collaboration is exemplified in the
UK national BIM library initiative [27];

- The existence of a specification librarian. As is the convention in physical library outfits, the need for a specification librarian is implied. At a broad level (state or national), the librarian's role would be necessary for ensuring the integrity as well as effective cataloguing and sustenance of the information content of each library product. Thus, it is conceivable that the head specifier within a local organizational unit can act in the capacity of the specification librarian as his traditional role would already furnish him with the skill set for interacting and updating a localized version of the product library.

Overall, augmenting building information models with specification parameters derived from product libraries optimize information storage, retrieval and reuse leveraging an external, albeit complimentary, 
platform. Furthermore, a library with a range of interoperable objects encourages lifecycle information use and coordination, thus enabling a paradigm shift in favor of specifications as important sources of information integral to building information models.

\section{Conclusions}

This paper argues and illustrates that building information models can be systematically augmented with parameters from product specifications. An overview of the building lifecycle was given and the benefits of BIM, both automational and informational were highlighted: Emphasis was placed on the latter as a justification for the chosen methodological approach.

Drawing on evidence from existing literature, an overview of current specification approaches was articulated with the aim of showing the challenges with current specification methods which principally comprise textual information. Thus, we propose a method which utilizes a product library as a repository for storing predefined specification parameters. By utilizing a COBie spreadsheet, we illustrated how predefined specification attributes of a BIM object (window) at different LODs can be integrated with the various phases of the building lifecycle.

Therefore, the approach demonstrated in this study holds significance for construction specification: (1) It emphasizes a non-text-intensive paradigm of reasoning about product specifications by creating a (BSL) framework for embedding specification parameters directly in BIM objects; (2) It highlights the merits of the concept of a building specification which evolves simultaneously with the building lifecycle as well as BIM objects at varying LODs.

Ultimately, further research in this area can explore methods for quantitatively determining the impact of the demonstrated approach on construction costs and schedule at specific points in the building lifecycle. This would provide a justification for BIM-based specification over and above current approaches
(Section 3).

\section{Acknowledgments}

This research was supported under Australian Research Council's Linkage Projects funding scheme (project number LP100200849). This paper contains references to a BIM model developed by the Project Services Department of the Queensland Government and alterations were merely for illustrative purposes and were done with the explicit permission of the model-owners.

\section{References}

[1] Azhar, S. 2011. "Building Information Modeling (BIM): Trends, Benefits, Risks and Challenges for the AEC Industry." Leadership and Management in Engineering 11 (3): 241-52.

[2] Succar, B. 2009. "Building Information Modelling Framework: A Research and Delivery Foundation for Industry Stakeholders." Automation in Construction 18 (3): 357-75.

[3] Fox, S., and Hietanen, J. 2007. "Interorganizational Use of Building Information Models: Potential for Automational, Informational and Transformational Effects." Construction Management and Economics 25 (3): 289-96.

[4] Potter, N. 2002. What Is a Designer?. London: Hyphen Press.

[5] Construction Specifications Institute. 2011. Construction Specifications Institute Practice Guide. New Jersey: John Wiley \& Sons.

[6] Bryde, D., Broquetas, M., and Volm, J. M. 2013. "The Project Benefits of Building Information Modelling (BIM)." International Journal of Project Management 31: 971-80.

[7] Manning, R., and Messner, J. 2008. "Case Studies in BIM Implementation for Programming of Healthcare Facilities." ITcon 13: 246-57.

[8] Azhar, S., Hein, M., and Sketo, B. 2008. "Building Information Modeling (BIM): Benefits, Risks and Challenges." Presented at the 44th Annual International Conference of the Associated Schools of Construction, Auburn, USA.

[9] Gelder, J. 2001. Specifying Architecture: A Guide to Professional Practice. 2nd ed. Australia: Construction Information Systems Australia Pty Limited.

[10] Chapman, I. 2011. "What Does Building Information Modelling (BIM) Mean for Specifications?." NBS (National Building Specification). Accessed May 1, 2012. 
http://www.thenbs.com/topics/bim/articles/bimforspecific ations.asp.

[11] Boukamp, F., and Akinci, B. 2007. "Automated Processing of Construction Specifications to Support Inspection and Quality Control." Automation in construction 17 (1): 90-106.

[12] The Cooperative Research Centre for Construction Innovation. 2009. National Guidelines for Digital Modelling. Brisbane: CRC (Cooperative Research Centre) for Construction Innovation.

[13] ASTM (American Society for Testing and Materials). 2014. ASTM E84-14, Standard Test Method for Surface Burning Characteristics of Building Materials. West Conshohocken: ASTM International.

[14] American Society for Testing and Materials. 2014. ASTM C1396/C1396M-14a, Standard Specification for Gypsum Board. West Conshohocken: ASTM International.

[15] Weygant, R. S. 2011. BIM Content Development: Standards, Strategies and Best Practices. Hoboken: John Wiley \& Sons.

[16] Chew, A., and Riley, M. 2013. What Is Going on with BIM? On the Way to $6 D$, edited by NATSPEC (National Specification System of Australia). Melbourne: Corrs Chamber.

[17] Kreider, R., Messner, J., and Dubler, C. 2010. "Determining the Frequency and Impact of Applying BIM for Different Purposes on Projects." In Proceedings of the 6th International Conference on Innovation in AEC (Architecture, Engineering \& Construction), 9-11.

[18] Ciribini, A. 2013. "Level of Detail and Level of Development: Commissioning Processes and Information Modelling." TECHNE_Journal of Technology for
Architecture and Environment 6: 90-9.

[19] American Institute of Architects. 2013. "Project Building Information Modelling Protocol." American Institute of Architects. Accessed May 3, 2014. http://www.aia.org.

[20] BIM Forum. 2013. "Level of Development Specification.” BIM Forum. Accessed December 3, 2013. http://bimforum.org/wp-content/uploads/2013/08/2013-L OD-Specification.pdf.

[21] International Facility Management Association. 2013. BIM for Facility Managers. New Jersey: John Wiley \& Sons.

[22] NATSPEC. 2013. "National BIM Object-Element Matrix." NATSPEC. Accessed March 3, 2013. http://bim.natspec.org/index.php/natspec-bim-documents/ national-bim-guide.

[23] Duddy, K., Beazley, S., Drogemuller, R., and Kiegeland, J. 2013. "A Platform-Independent Product Library for BIM." In Proceedings of the 30th CIB W78 International Conference, 389-99.

[24] Gonzalez, M. C. 2011. "List of BIM Software \& Providers.” CAD-Addict. Accessed January 7, 2012. http://www.cad-addict.com/2010/03/list-of-bim-softwareproviders.html.

[25] BIM Industry Working Group. 2011. A Report for the Government Construction Client Group. London: Cabinet Office.

[26] Utiome, E., and Drogemuller, R. 2013. "An Approach for Extending Building Information Models (BIM) to Specifications." In Proceedings of the 30th CIB W78 International Conference, 290-9.

[27] NBS. 2014. "NBS National BIM Library.” NBS. Accessed June 6 , 2014. http://www.nationalbimlibrary. com/. 